provement had become stationary, this gentleman recom. provement had become stationary, the furnished her with a mended her to try hypnotism, and furnished her with a letter of introduction to me, detailing the history of her case. On examination, I found no apparent physical ims perfection to account for the impaired vision; nor was there any pain about the head or eyes. The eyes had very much the appearance of an incipient case of amaurosis, only the pupils were nct quite so much dilated. I suspected that the cause of the impaired vision was a want of sufficient that the cause of the impaired in and, if so, that hypnotism would very soon relieve her. My first object was to apply test by which I might be enabled to ascertain what amount of benefit had resulted from my processes. On presenting the title-page of a book to her, with the largest and boldest letters in my room, I found she could not discern a single letter, notwithstanding there were some letters quarter of an inch long, and very bold open print. Having hypnotised the patient and directed the nervous power to the eyes, by wafting over them, and gently power to the eyes, by wafting occasionally, so as to keep up a sustained touching them occasionally, so as to the patient's mind to her eyes and the act of atten vision, she was aroused in about ten minutes. I now presented before her the title-page of the same book, when she instantly exclaimed, with delight and surprise, "I see the word commerce!" pointing to it. I told her she would see more than that presently; and in a little while she exclaimed "I see commercial"; then "I see dictionary"; and shortly after, "I see McCulloch", the name of the author; but she could see nothing more. I told her that, after a little rest, I felt assured she would see still smaller after a little rest, don, Longman, Green, and Longmans". Such was the result of my first process. After a second hypnotic operation, next day, the patient could read, when first aroused, the whole of the title-page of a pamphlet; and, in about five minutes after, she read two lines of the text. After another operation, the same day, she could read the small close print in the appendix; and was able the same evening to write a letter home reporting progress, for the first time for twelve months. She only required two more hypnotic operations, when she was found able to read the smallest sized print in a newspaper; after which she left me, quite cured, and, as I have heard, she has continued well ever since.

None of these last five patients took any medicine whatever whilst under my care, nor had they any external application; which, therefore, with the shortness of the time they were under treatment, leaves no doubt but hypnotism and their cures stood towards each other in the relation of cause and effect.

Whilst I have been so far successful in producing important results of a practical nature in the relief and cure of certain diseases by hypnotism, I do not wish to hold it up as a panacea or universal remedy. Indeed, I do not believe in any universal remedy. Moreover, it is well known that I use hypnotism aloue only in a small number of cases, to which I have found it particularly adapted; and that I use it in other cases in conjunction with the exhibition of medicines; whilst, in the great majority of cases, I do not use hypnotism at all, but adopt the ordinary mode of practice, by prescribing medicines in such doses as are calculated to produce obvious physiological effects. Moreover, I do not pretend by hypnotism to have the power of ren dering patients clairroyant, and capable of manifesting what are called the higher phenomena of Mesmerism. These feats are quite beyond the range of my power and humble pretensions; and, indeed, such pretensions comprise phenomena which are not only at variance with reason and common sense, but such as, if true, would actually upset the whole fabric of society in the present state of our existence. But, independently of this $a$ priori argument against the probability of such pretensions being true, I have still stronger reasons for being sceptical on the point, for I have had many opportunities of investigating the pretensions of some of the most noted clairvoyants in Europe; but, from my knowledge how to guard against probable sources of fallacy, every one of them broke down; which surely would not have been the case, had they really possessed the transcendental gifts attributed to them.

Rylan House, Manchester, August 1858.

\section{EDUCATION IN PAROCHIAL SCHOOLS: ITS INFLUENCE ON INSANITY AND MENTAL ABERRATION.}

\section{By GEORGE KING, Esq.}

THE alarming increase of mental excitement in all classes of society, and the frightful and often fatal consequences that are daily occurring from its effects, are subjects that, in $\mathrm{my}$ opinion, may be legitimately brought before the medical Association, for their consideration members of a Medical ave many members in the Bath and and discussion, as we have many members in the Bath and Bristol Branch who have the care and control of insane patients, and who make the treatment of mental disorders their more immediate study. I had intended bring o the subject forward at our last Branch meeting; but, remembering that it was the annual meeting, when there is generally but little time for discussing

sending it to the JourNal at once.

My object in directing the attention of the readers of the Association JodRNaL to mental disorder and insanity is more with a view to elicit from them. The subject is one of the cause, than to publish my owh. The and to the profession. The building of so many lunatic asylums, and the increase of our poor-rates, in consequence of the increase of insanity amo the lower and middle classes of the community, and the filling of our union houses with imbecile paupers, and the crowding of our gaols with criminal lunatics, do not, and have not, in my opinion, attracted that attention from the medical profession and ratepayers that they deserve.

I have frequently thought that we do not seem to have near so much command over the mental disorders of our patients as over the functional and bodily ailments. Medical men have but few remedies or curative means; and I believe that the general practitioner, as well as the physician, is as much at fault and at a loss as the bystanders how to proceed when they come to treat this important class of human affections. Still, we may sometimes be able to control the patient, at the same time relieving and advising with the anxious relatives. The public, the government, and the judges of the land, will very naturally look to medical men, and expect from them some explanation; and we ought to be prepared with information as to some of the causes that produce this unfortunate aberration of mind, which terminates in insanity. It is quite within the province of a physician to be able to form some idea of the causes, as well as to be prepared with some practical exposition of the predisposition to, as well as what may be done for the prevention of, insanity. Iamentable experience has taught us that, with all our acquirements and scientific and practical knowledge, it avails us but little in our endeavours to tranquillise these turbulent spirits, or to "administer to minds diseased". It is a distressing and painful reflection, that man, the noblest work of God, should be reduced to the state of the brute creation, without our being able to administer to its relief. This is a great reproach to our profession, as well as to our professional attainments, and should therefore occupy our deepest thoughts, and excite us to a most earnest consideration of the subject; it should direct our attention to the effects which the cultivation of the mind, especially in the young, may have on the health of the body. The doctrine of influences and exciting causes, and their effects on the mental organs and nervous system, is a subject, in connexion with insanity, that requires to be more deeply studied.

I shall not in this paper enter on the pathology of insanity, nor allude to the various supposed causes assigned by others for the great increase of it in this country; but I 


\section{anl it mes matrally bo expected that I should state my core convietions and riews on the subjeot.}

The noalesness, I believe, and oven danger, of the very early attompts to cultivate the minds of children to such a high degree as is pursued in their instruction in the present das, is a subject that is not thought of by those who have the care and instruction of the young. The most useful mode of education is that which cultivates every part of man's nature, and not the mind exclusively. To force the memory before the brain is fully developed, is the same as to fatigue the muscles by hard work. The close connexion between mind and body appears to be unknown or forgotten by those who undertake to teach the young. They seem to think that, in exciting the mind, they are exciting something totally independent of the body. In their attempts to produce a prodigy, they get an idiot. Professor Broussais, writing on this subject, says: "Intellectual labours give rise, in early life, to effects corresponding with the actual state of the individual constitution. Thus the brain, the growth of which is not complete, acquires, by the exercise of thought, an extraordinary energy and volume; the moral faculties become truly prodigious; but this advantage is sadly counterbalanced by cerebral infiammations, which give rise to hydrocephalus, and by a languor in the rest of the body, the development of which remains imperfect."

If the philanthropists who sympathise so much for the boys and girls - who, no doubt, are too much overworked in our factories-would visit some of our union and parochial schools, they would find children, who were naturally of a lively temperament, sullen and degenerating in health, from too much mental pressure having been put on. Dr. Johnson, in his Economy of Health, on the education of children, says: "Their young ideas, instead of being often left to shoot, are forced out rapidly, to the great detriment of the intellectual soil, thus exhausted by too early and too frequent crops." M. Ratier, in an essay on the Physical Edrucation of Children, which was crowned by the Royal Society of Bordeaux in 1821 , thus speaks of early mental instruction: "The labour of the mind to which some parents subject their children, not only too soon, but in a wrong direction, is often the cause of their bad health, and causes nearly all those who are distinguished by precocity of the intellectual faculties to perish prematurely; so that we seldom see a perfect man-that is, one who exhibits an equilibrium of the physical, mental, and moral faculties." By premature efforts to improve the powers of the intellect, the organ in which they reside is exhausted. The early acquirements are not to be gained without destruction of health; and our obituaries tell us that the highly gifted intellects are generally short-lived. This is a grave reflection, deserving the serious consideration of all who have influence to perpetuate or allay the excitement alluded to.

Intellectual cultivation and powerful mental excitement have a very important bearing upon insanity ; and it is, I believe, acknowledged by all, that mental derangement and insanity now prevail to a much greater extent in this than in any other country in Europe. The increase in our union houses of imbecile and idiotic paupers is frightful. Diseases of the heart are also more frequently met with in practice than formerly. The powerful and irregular operation of the passions, and too much study, may be considered one of the causes likely to produce organic diseases of the heart. If such are the effects and serious consequences of thus early rigorously cultivating the minds of children to such a high degree, particularly those who, by their position in society, are designed for and ought to be prepared to fill menial offices, it certainly becomes a serious public question whether such a mode of training should be persisted in in our parochial schools. I believe that the brain and the mental functions generally are too early excited.

I have often thought that the high character of the education which is given to the children in our union and parodtiial schools at the present day may be one of the mang canes that is likely to produce the great mental excitement and disondered state of mind among the lower claseses of the community. They are not educated for the position of life they may be placed in, or to perform the duties they are likely to be called on to do. In these schools, the poor young creatures are so stuffed and crammed by the present forcing system, that their eyes are ready to start out of their heads, which keeps them in perpetual danger of intellectual apoplexy. If the faculty of thinking be too much excited, or becomes too energetic, the consequence will be, according to circumstances, various degrees of hallucination or inordinate desires, such as hypochondriasis or monomania; and in females, nymphomania. If, on the contrary, too dull, the consequence will be a defect, to a greater or less degree, of certain natural faculties or propensities. Observation, and the history of the most distinguished men, lead us to the conclusion that early mental culture is not necessary in order to produce the highest power of mind. There is scarcely an instance of a great man who has accomplished great results, and has obtained the gratitude of mankind, who in early life received an education in reference to the wonderful works and good he afterwards performed. It was to self-teaching in after life that they were indebted for the development of their great powers.

Thus we see, that to make great men, it is not necessary or proper to commence with the infant, and tax his feeble powers of mind and injure his physical development by early education. Although mental excitement may not often produce insanity in children, it may predispose them to an attack of this disease, by giving an early predominance to the nervous system. There may be but few instances of children or adults becoming insane, though they do occasionally occur by too early cultivating their young minds, or from strong mental excitement and injudicious development of the moral functions, particularly intelligent, forward, and precocious children; and there are some instances recorded of children as young as ten or twelve ycars becoming mad from this mode of instruction. Mental precocity is generally a symptom of disease; and hence those who exhibit it fro quently dic young. The predisposition to insanity usually developes itself on approaches to adult age; guardians, therefore, whose duty it is to bring up children so that they may get their own bread, should see that nothing is done to foster this predisposition. They should bear in mind that pauper children ought to be educated for domestic services, and not for professions. It is to be regretted that so much of the poor rates should be spent in giving those poor children a superior education, and in teaching them what can never be of any use to them in the situations they will most likely be called to fill. After being thus educated, to place them out in situations for which they have never been trained, is trifling with their feelings. Let them be taught to well perform the duties that properly belong to home and society; they will then become valuable and useful members of the community, instead of inmates of mad-houses. To rive pauper children a high mental education, and then to cause them to become associates of the class of persons that generally apply for them, and to send them out into menial situations, such as they are usually called to occupy, and for which, unfortunately, their guardians have not prepared them, is unjustifiable and cruel. What mortification these poor things must have to endure, and what difficulties must they be called on to contend with, as with wearied bodies and disturbed minds they go on with their irksome work, reproaching those who had thus misinstructed them, and lamenting their unhappy and degraded condition, suffering the most intense mental anguish, till the mind gives way, and the sensorium becomes disorganised. The nervous system is rendered morbid and irritable, and, ultimately, a dorangement in the manifestations of the mental faculties ensues; this becomes hereditary, by which their posterity are contaminated. If such, then, be the serious consequences and frightful effects of the early tampering with the mental functions, surely it is a subject which ought to engage the attention of the medical profession and the public.

The inutility of too early cultivating tho mind, and its 
ovil reaults, hare been noticed by observing men not belonging to the medical profession. Cobbett, in his Advice to Young Men, a work abounding with rich and excellent remarks upon the rearing and educating of children, observes: "The mind, as well as the body, requires time to come to its natural strength; and the way to have it possess at last its natural strength is not to attempt to load it too soon, and to favour it in its progress by giving to the body good and plentiful food, sweet air, and abundant exercise, accompanied with as little discontent and uneasiness as possible." Another popular writer says: "Knowledge should only keep pace with the natural growth of the human faculties. When I see a little urchin, who ought to be enjoying nature's holiday, and strengthening his constitution by wholesome exercise to bear the vicissitudes of the world in after times, kidnapped and sent to school, to sit on a bench for four or five hours together, employed in learning by rote what he is unable to comprehend, I cannot help contemplating him as the slave and the rictim of the ranity of the parent and the folly of the teacher. Such a system is only calculated to lay a foundation for disease and decrepitude, to stunt the physical and intellectual growth, and to produce a premature old age both in body and inind." The brain is the material organ by which all the mental faculties are manifested. In children, it is but partially developed; over excitement of it when in this state is extremely dangerous. For the guardians to send young girls from the union out into situations to be occupied in nursing and singing "lullaby" to a dirty little cross child in a garret, or "All in the Downs" in a scullery, after they have been taught singing, and studying geography, and occupied in tracing the map of Palestine, to enable them to study the Scriptures, is doing them a serious mental injury, and a moral wrong; it is trifling with their feelings, and is calculated to interfere with the functions of the brain in such a manner as to make them miserable and unhappy all their lifetime. When a member of the Board of Guardians, I recollect that application was made by the schoolmaster of the union for music paper to teach the children singing, and I was cruel enough to oppose the grant. I do not object to these poor young creatures singing the praise of God to the tune of the Old Hundredth, or Erening Hymn, but I think they should be able to do it without the notes. The Poor-Law Conmissioners never intended that the poor-rates should be appropriated to forming singing classes in the Union House, or be spent in decorating the walls of the schoolroom with maps.

The stuffing and over-cramming of the head of an unwilling and stubborn pauper boy with mental knowledge is not likely to make him more lively or contented in the position in life he is likely to be placed. But $I$ fear it is likely to produce a sadness and perverseness of disposition, which may and is likely to generate into a morbid state of the brain, which would in all probability end in insanity. To send such a boy out to be stuck on a seat from six in the morning till ten at night for seven years, to be kept in check by violence and fear, under the strict eyc of a disciplinarian tailor or shoemaker, who, because he is "only a pauper who nobody owns", think they may have their "pound of flesh" out of him, is a kind of treatment (after giving him almost a classical education) too much for a youthful mind to bear, and too much pressure on a vital organ just budding into maturity. This is cruel, and I consider criminal, on the part of those who stand in loco parentis. Their olject should be to make the children happy and contented when sent out into the world. This should be done by teaching them that that best fits their capacities, and to make them fully know and practise the business which belong to their stations. To create a taste and a craving for the grapes out of reach will never make them happy or contented.

A celebrated writer says: "Moral and religious training is of the first importance; other knowledge will take care of itself." Give them this impulse, it will manifest itself; let the pauper children be only thus instructed, and they
Fill be sure to find their way through the world, and will be happy and contented in whatever situation they may bo placed, and mental derangement and insanity prevented. The aim and object of pauper education ought to be to fit them for the sphere of life for which their studies and circumstances seemed to have intended them. Such emulation, encouraged in our union schools among the pauper children, must have a mischievous influence over their future prospects, instead of preparing them for domestic services, and to become useful members of society. A writer in one of our periodicals, in describing a young woman thus educated, says: "They marry, and know not how to keep their houses, how to cater,-no home comforts. The husband comes to an unclean house, a bad fire, an ill-dressed dinner; the wife has never learnt that first most necessary businesshow to cook. What is the consequence? The unsatisfied husband is put out of humour; he quits the house which has ceased to be a home. And where does he go ? Not far off is a public-house,-a clean room and sanded floor, etc., bright fire, and irresistible temptations. He meets others there like himself, driven out and tempted in, and the very first day makes him an incipient 'sot', and the sequel naturally is delirium tremens and insanity."

I have gone further into the question of education then I intended; and I fear I shall be suspected by the educationists of being opposed to education; but that is not the case. It is to the period when it ought to be begun, and the characters that are to be trained, and the effects on the physical and mental energies, to which I am opposed. It is to the taxing the brain before it is sufficiently consolidated, and its serious consequences, that I am most anxious to draw the nttention of the members of the Association; and I believe it is legitimately a medical question. "Order is IIeaven's first law ;" for the want of this, the best intentions and education may be rendered useless. If order, regularity, and punctuality were more rigidly enforced, and more practical teaching in our parochial and union schools, and less mental training, I believe there would be less crime and less insanity in the country.

Bath, July 1855.

\section{CASE OF POLYPUS OF THE UTERUS: REMOVAL BY LIGATURE: WITH REMARKS.}

By WII.LIAM WEBB, M.D., M.R.C.S.Eng., late HouseSurgeon to the Staffordshire General Infirmary.

PonxpI of the uterus are not infrequently met with among married females, as well as among those who have livea to the age of forty and upwards, and have led a life of celibacy; and, although cases somewhat analogous to the one I an about to record are to be found in the pages of the medical periodicals and elsewhere, nevertheless, as this case has interested me very much, it may not be entirely devoid of interest to other practitioners.

Iy partner, Mr. Cantrell, requested me to accompeny Mr. Fearn, of Derby, and himself, on Saturday, July 28th last, for the purpose of rendering assistance in the removal of one of these growths. He had been called to the case only a day or two before, and had only made one examination; and, although the substance closed pretty fully the cavity of the vagina as far as it reached, he felt satisfied that it had a pedicular attachment either to the os or the cervix uteri, and that its structure was of a fibrous aharacter. The history of the case is as follows.

CAsE. Miss $H$., aged 47 , the sister of a farmer residing five miles from Wirksworth, a person of pale chlorotic appearance, and of leuco-phlegmatic temperament, had been suffering for upwards of seven years from a "dragging sensation" in the womb, some slight pain, and copious hæmorrhagic discharges recurring at very frequent periods; indeed, of late she had scarcely becn a day without much discharge. At the commencement of these symptoms, she consulted : surgeon, who told her that she was the subject of polypue, 